\title{
On-pump versus off-pump coronary artery bypass surgery in patients with preoperative anemia
}

\author{
Domenico Paparella, MD, ${ }^{\mathrm{a}}$ Pietro Guida, $\mathrm{PhD},{ }^{\mathrm{b}}$ Giuseppe Scrascia, $\mathrm{MD}, \mathrm{PhD},{ }^{\mathrm{c}}$ Vitantonio Fanelli, $\mathrm{MD},{ }^{\mathrm{d}}$ \\ Marco Contini, MD, ${ }^{\mathrm{d}}$ Salvatore Zaccaria, $\mathrm{MD},{ }^{\mathrm{c}}$ Giuseppe Labriola, MD, ${ }^{\mathrm{e}}$ Carmine Carbone, MD, \\ Florinda Mastro, $\mathrm{MD},{ }^{\mathrm{a}}$ and Valerio Mazzei, $\mathrm{MD}^{\mathrm{f}}$
}

\begin{abstract}
Objectives: The study objective was to evaluate the effects on early outcome and midterm survival of performing coronary artery bypass grafting with the off-pump technique in comparison with cardiopulmonary bypass (on-pump) in patients with preoperative anemia.

Methods: Consecutive adult anemic patients (preoperative hemoglobin $<13.0 \mathrm{~g} /$ $\mathrm{dL}$ in men and $<12.0 \mathrm{~g} / \mathrm{dL}$ in women) resident in Puglia region who underwent isolated coronary artery bypass grafting between January 2011 and November 2013 were considered. Vital status was ascertained from the date of surgery to December 31, 2013. Odds ratio and hazard ratio (HR) were estimated. Propensity score methods were used to control for confounders.
\end{abstract}

Results: Of 939 anemic patients (234 female, aged $71 \pm 9$ years), 361 underwent operation with the off-pump technique and 578 underwent operation with the onpump technique. Patients undergoing off-pump coronary artery bypass had a shorter intensive care unit length of stay, lower blood transfusion rate, and postoperative reduction in creatinine clearance. During a median follow-up of 18 months, 126 patients died: 46 in hospital (35 on-pump) and 80 after discharge (33 on-pump). In comparison with the off-pump technique, the on-pump technique had greater hospital mortality (odds ratio, $2.57 ; P=.028$ ) and 30-day incidence of fatal events (HR, 2.67; $P=.026)$. After a period without risk differences between groups (1-6 months; HR, $0.79 ; P=.618$ ), a lower mortality in those undergoing the on-pump technique was detected (after 6 months HR, 0.35; $P=.014)$. All results were confirmed in the 157 pairs of patients matched for propensity score, anemia grade, and surgery center.

Conclusions: In patients with low levels of preoperative hemoglobin, off-pump coronary artery bypass was associated with lower early morbidity and mortality but a greater risk of mortality during follow-up compared with on-pump coronary artery bypass. (J Thorac Cardiovasc Surg 2015;149:1018-26)

Supplemental material is available online.

\footnotetext{
From the Division of Cardiac Surgery, ${ }^{\text {a }}$ Department of Emergency and Organ Transplant, University of Bari Aldo Moro, Bari, Italy; Puglia Health Regional Agency, ${ }^{\mathrm{b}}$ Bari, Italy; Department of Cardiac Surgery, ${ }^{c}$ Vito Fazzi Hospital, Lecce, Italy; Department of Cardiac Surgery, ${ }^{\mathrm{d}}$ Villa Verde Hospital, Taranto, Italy; Department of Cardiac Surgery, ${ }^{\mathrm{e}}$ Santa Maria Hospital, Bari, Italy; and Department of Cardiac Surgery, ${ }^{\mathrm{f}}$ Mater Dei Hospital, Bari, Italy.

Received for publication Oct 3, 2014; revisions received Nov 26, 2014; accepted for publication Dec 20, 2014; available ahead of print Feb 1, 2015.

Address for reprints: Domenico Paparella, MD, Division of Cardiac Surgery, Department of Emergency and Organ Transplant (D.E.T.O.), University of Bari "Aldo Moro," Piazza Giulio Cesare 11, 70100 Bari, Italy (E-mail: domenico. paparella@uniba.it).

0022-5223/\$36.00

Copyright (C) 2015 by The American Association for Thoracic Surgery

http://dx.doi.org/10.1016/j.jtcvs.2014.12.049
}

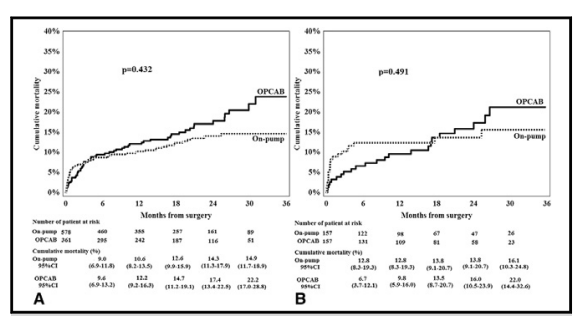

In anemic patients, the initial advantages of OPCAB are counterbalanced by worse survival during follow-up.

\section{Central Message}

Preoperative anemia is a risk factor for mortality and adverse outcome in patients undergoing coronary artery surgery. In anemic patients, OPCAB is associated with reduced operative mortality/ morbidity; however, the initial advantages are counterbalanced by decreased survival during follow-up compared with on-pump surgery.

\section{Perspective}

The presented data impose 2 different considerations. First, the performance of CPB should be optimized to reduce short-term adverse events in anemic patients. The use of miniaturized CPB equipment, with reduced hemodilution and transfusion requirements, may lead to improved outcome. Second, OPCAB technique should provide documented complete and adequate myocardial revascularization to improve long-term survival.

See Editorial page 962. 


\section{Abbreviations and Acronyms \\ $\mathrm{CABG}=$ coronary artery bypass grafting \\ $\mathrm{CI}=$ confidence interval \\ $\mathrm{CPB}=$ cardiopulmonary bypass \\ euroSCORE $=$ European System for Cardiac \\ Operative Risk Evaluation
HR = hazard ratio
ICU = intensive care unit
OPCAB $=$ off-pump coronary artery bypass \\ OR $\quad=$ odds ratio}

Preoperative anemia is associated with a number of comorbidities, including advanced age, female gender, small body surface area, poor left ventricular ejection fraction, renal function impairment, congestive heart failure, unstable angina, and others, ${ }^{13,14}$ all of which are recognized risk factors for adverse outcome after cardiac surgery. Postoperative morbidity and mortality after cardiac surgery, specifically after CABG, are higher in anemic patients, ${ }^{13-16}$ and when preoperative anemia is added to risk classification scores, it improves their discrimination ability. ${ }^{17}$ Differences in postoperative outcomes between on-pump and OPCAB techniques have not been studied in patients with preoperative anemia. The aim of the present study was to compare in-hospital morbidity and shortterm and midterm survival in patients with preoperative anemia undergoing on-pump coronary artery bypass or OPCAB surgery.

\section{MATERIALS AND METHODS Study Population}

Preoperative, intraoperative, and postoperative information on consecutive adult patients who underwent isolated CABG from January 1, 2011, to November 30, 2013, were gathered from the Puglia Regional Adult Cardiac Surgery Registry. The study is an initiative of the Health Regional Agency of Puglia region, which has been described. ${ }^{18}$ Briefly, by implementing an accurate database including prospectively clinical information and details on cardiac surgical procedures, the aims of the study were the evaluation of short- and long-term results of heart operations performed at the 7 adult cardiac surgery centers in the Puglia region (University of Bari-Policlinico Hospital Coordinating Centre, Anthea Hospital in Bari, Santa Maria Hospital in Bari, Villa Bianca Hospital in Bari, Villa Verde Hospital in Taranto, Vito Fazzi Hospital in Lecce, and Città di Lecce Hospital in Lecce). The study was conducted in accordance with the Declaration of Helsinki. According to institutional review board policy, it was determined that the research did not require informed consent. Hospital mortality risk prediction was carried out for each patient according to the European System for Cardiac Operative Risk Evaluation (euroSCORE) II model. ${ }^{19}$ Anemia was classified according to the preoperative hemoglobin level evaluated on the day of surgery. Patients with anemia according to the World Health Organization criteria were included. ${ }^{20}$ Men with a hemoglobin level of 13.0 $\mathrm{g} / \mathrm{dL}$ or greater and women with a hemoglobin level of $12.0 \mathrm{~g} / \mathrm{dL}$ or greater were excluded. Anemia was classified as (1) mild if hemoglobin was 11.0 to $12.9 \mathrm{~g} / \mathrm{dL}$ in men and 11.0 to $11.9 \mathrm{~g} / \mathrm{dL}$ in women; (2) moderate if hemoglobin was 8.0 to $10.9 \mathrm{~g} / \mathrm{dL}$ in both genders; or (3) severe if hemoglobin was less than $8.0 \mathrm{~g} / \mathrm{dL}$ in both genders. Two of 7 cardiac surgery units of region were excluded from the analysis because of systematic missing preoperative hemoglobin values.

\section{Surgical Management}

The conventional surgical approach was median sternotomy in most of the CABG procedures. Heparin was injected as a single bolus of $300 \mathrm{U} / \mathrm{kg}$ in on-pump procedures and $150 \mathrm{U} / \mathrm{kg}$ in OPCAB to obtain an activated clotting time of 400 and 300 seconds, respectively. An additional heparin bolus of 5000 units was injected if the activated clotting time decreased below these targets. After surgery, protamine sulfate was administered to neutralize heparin $(1 \mathrm{mg}$ protamine/100 $\mathrm{U}$ of heparin in on-pump procedures and $0.8 \mathrm{mg} / 100 \mathrm{U}$ of heparin in OPCAB). CPB was established with aortic cannulation and right atrial cannulation with 2-stage cannula. Deep pericardial suture, heart stabilizer, intracoronary shunts, or snares were used to stabilize the heart and allow bloodless anastomoses according to the surgeon's preference. Patients with hemoglobin values less than $8 \mathrm{~g} / \mathrm{dL}$ received transfusions after the induction of anesthesia. Indications for intraoperative homologous blood transfusion were hemoglobin less than $7 \mathrm{~g} / \mathrm{dL}$ or hematocrit less than 0.21 to 0.22 , and the postoperative cutoff was hemoglobin less than $8 \mathrm{~g} / \mathrm{dL}$ or hematocrit less than 0.23 to 0.24 .

\section{End Point}

The primary outcome was hospital mortality, defined as death occurring at any time after surgery during the hospital period in which the operation was performed. The secondary end point was hospital morbidity. The coprimary end point was midterm mortality. Vital status and dates of death to December 31, 2013, were obtained for resident in Puglia by linking regional Health Information System to the registry on the basis of an encrypted patient identifier. Follow-up was considered to be administratively censored on December 31, 2013, and was at least 1 month for all patients (maximum, 36 months).

\section{Statistical Analysis}

Data are shown as mean values \pm standard deviation, and categoric variables are given as percentages. Because of the low number of patients with severe anemia, 2 anemia grades were analyzed: mild and moderate to severe. Intraoperative conversion from off-pump to on-pump CABG was analyzed according to the intention-to-treat principle based on the initial treatment assignment group (OPCAB). Preoperative patients' characteristics and individual risk factors were analyzed using a mixed model with centers fitted as random so that possible differences in data across surgical units could be considered. To control for selection bias as a result of nonrandom treatment assignment, the propensity analysis method was used to estimate the probability of being assigned to on-pump surgery. ${ }^{21}$ A multivariate mixed logistic regression model was developed including all risk factors and preoperative variables associated with the type of surgery. We matched participants, stratified by anemia grade, on the basis of closest propensity score $(<0.15$ in matched pairs). We used an automated matching procedure that for each $\mathrm{OPCAB}$ case selected 1 on-pump case that fulfilled the matching criterion. Patients were initially matched within the same cardiac surgeon, with the remaining patients who were matched by center.

In the entire sample, in-hospital mortality was analyzed by using mixed logistic regression analysis adjusting for linear predictor of propensity score. ${ }^{21}$ For the propensity analysis that required statistical methods appropriate for matched data, a conditional logistic regression model was used considering the pairs of selected patients. Odds ratios (ORs) for inhospital mortality were estimated (on-pump vs OPCAB). The cumulative mortality curves, based on Kaplan-Meier analyses stratified by type of surgery, were compared with the Wilcoxon test. Survival analysis was performed by using Cox proportional hazards model with stratification by surgical center. Because of significant evidence against the proportional hazards assumption for the overall survival from surgery, we estimated separate hazard ratios (HRs) for each of the following time intervals 
from the date of procedure: 0 to 30 days, 1 to 6 months, and more than 6 months. The first cut point (30 days) is one of the most frequently used definitions of operative mortality for analyses of short-term mortality after cardiac surgery. The second interval may be considered as the early postoperative period representative of the most seriously ill patients. ${ }^{22}$ We fitted 3 separate Cox regression models that were conditional on being alive at the beginning of each time interval. Confidence intervals (CIs) at the level of $95 \%$ were provided for OR and HR estimations. To evaluate whether anemia grade influenced mortality risk, each predictive model was also evaluated by including an interaction term. Statistical significance of the interaction between anemia grade and surgical technique in predicting mortality was tested using the likelihood ratio test by including the 2 variables and their cross-product term in the same multivariate model. The analyses were performed using STATA software, version 12 (StataCorp LP, College Station, Tex).

\section{RESULTS}

\section{Study Population}

A total of 2835 patients underwent CABG surgery; 35 patients $(1.2 \%)$ with missing preoperative hemoglobin values were excluded. Of 2800 patients, 1013 (36.2\%) had preoperative anemia. Anemia was significantly more frequent in OPCAB than on-pump surgery cases $(41.9 \%$ vs $33.6 \% ; P<.001)$. Seventy-four patients $(7.3 \%)$ who were not residents of the Puglia region were excluded. The final study population included 939 patients (234 female, aged $71 \pm 9$ years); 361 underwent OPCAB, and 578 underwent on-pump. Anemia was mild in 651 patients $(69.3 \%)$, moderate in 283 patients $(30.1 \%)$, and severe in 5 patients $(0.5 \%)$. Of 361 patients undergoing OPCAB, $244(67.6 \%)$ had mild anemia, $113(31.3 \%)$ had moderate anemia, and $4(1.1 \%)$ had severe anemia. Among the 578 patients undergoing on-pump surgery, $407(70.4 \%)$ had mild anemia, $170(29.4 \%)$ had moderate anemia, and 1 $(0.2 \%)$ had severe anemia. Intraoperative conversion from OPCAB to on-pump surgery occurred in 13 patients. Median sternotomy was the surgical approach in all onpump procedures and in $355(98.3 \%)$ OPCAB procedures. In the on-pump surgery group, cardioplegic solution was blood-based in $99.3 \%$ of procedures, cold in $59.7 \%$ of procedures, antegrade in $88.4 \%$ of procedures, and both antegrade-retrograde in $11.2 \%$ of procedures, with $81 \pm$ 29 minutes and $49 \pm 21$ minutes for CPB and crossclamp duration, respectively. Table 1 shows the preoperative characteristics of patients according to CABG technique. In comparison with patients undergoing the on-pump technique, patients undergoing $\mathrm{OPCAB}$ were significantly older, with a greater prevalence of hyperlipidemia, renal impairment, extracardiac arteriopathy, previous percutaneous coronary intervention, lower preoperative hemoglobin, lower number of diseased vessels, and anastomoses performed.

\section{Propensity Score Matching}

Propensity score successfully matched 157 on-pump cases to 157 OPCAB cases (model details in Table
E1). The score performed well in balancing measured confounders: There was no significant difference between matched patients with regard to preoperative characteristics (Table 1) and in mean propensity score $(0.53$ vs 0.54$)$.

\section{Postoperative Outcome}

Table 2 shows the postoperative outcome according to study groups. The total hospital length of stay was $10 \pm$ 13 days versus $12 \pm 11$ days $(P<.001)$ for OPCAB and on-pump surgery, respectively. In the entire sample adjusting for propensity score, OPCAB cases had a shorter stay in the intensive care unit (ICU) and a lower rate of postoperative red blood cell transfusions and postoperative creatinine clearance reduction. The total ICU length of stay was $2.9 \pm 4.2$ days in OPCAB cases and $3.4 \pm 6.4$ days in on-pump cases $(P=.004)$. In the propensity-matched group, patients undergoing OPCAB had a shorter stay in the ICU and a lower rate of postoperative red blood cell transfusions.

\section{Hospital Mortality}

During hospital admission, 46 patients died (euroSCORE II $3.7 \%$ ): 35 patients $(6.1 \%$, euroSCORE II $3.4 \%)$ in the on-pump group and 11 patients $(3.1 \%$, euroSCORE II $4.1 \%$ ) in the OPCAB group. The estimated effect of the on-pump technique over in-hospital mortality was quantified by an unadjusted OR of $2.10(95 \% \mathrm{CI}$, 1.03-4.28; $P=.042)$ and $2.57(95 \% \mathrm{CI}, 1.11-6.01$; $P=.028)$ after correction for propensity score. The analysis corrected for anemia grade confirmed the greater mortality in the on-pump group compared with the OPCAB group (OR, 2.16; $P=.035$ and $\mathrm{OR}, 2.61 ; P=.027$ for the model with anemia and the model with anemia and propensity score, respectively) without interaction between the surgical technique and the anemia grade (likelihood-ratio test for the interaction $P=.316$ and $P=.322$ for the model with anemia and the model with anemia and propensity score, respectively). In the matched group, inhospital mortality was observed in 17 patients $(5.4 \%)$. In comparison with $\mathrm{OPCAB}$, a significantly greater incidence of fatal events was observed in the on-pump group (13 vs 4 deaths; $8.3 \%$ vs $2.6 \%$ ) with an OR of $2.58(95 \%$ CI, 1.13-14.2; $P=.032$ ). In-hospital mortality was greater, but not significant, in moderate-to-severe anemia than in mild anemia $(6.3 \%$ vs $4.3 \%, P=.200$ in the entire sample and $10.2 \%$ vs $7.4 \%, P=.557$ in the matched group).

\section{Overall Mortality}

During a median period of 18 months, 80 fatal events were detected after the discharge: 33 in the on-pump group and 47 in the OPCAB group. A total of 126 patients died as a result of the surgery through December 31, 2013: 
TABLE 1. Characteristics of patients according to coronary artery bypass grafting technique in the entire sample and in propensity-matched groups

\begin{tabular}{|c|c|c|c|c|c|c|}
\hline & \multicolumn{2}{|c|}{ Entire sample } & \multirow[b]{3}{*}{$P$ value } & \multicolumn{2}{|c|}{ Propensity matched } & \multirow[b]{3}{*}{$P$ value } \\
\hline & On-pump & ОРСАВ & & On-pump & ОРСАВ & \\
\hline & $\mathbf{n}=\mathbf{5 7 8}$ & $\mathrm{n}=\mathbf{3 6 1}$ & & $\mathbf{n}=157$ & $\mathbf{n}=157$ & \\
\hline Age $(y)$ & $70 \pm 8$ & $72 \pm 9$ & .010 & $71 \pm 8$ & $71 \pm 9$ & .784 \\
\hline Female gender & $25.8 \%$ & $23.5 \%$ & .419 & $27.4 \%$ & $22.9 \%$ & .347 \\
\hline Body mass index $\left(\mathrm{kg} / \mathrm{m}^{2}\right)$ & $27.4 \pm 4.1$ & $27 \pm 4.2$ & .100 & $27 \pm 4.2$ & $26.9 \pm 4.1$ & .701 \\
\hline Hypertension & $80.4 \%$ & $85.3 \%$ & .696 & $82.2 \%$ & $82.8 \%$ & .891 \\
\hline Hyperlipidemia & $54.8 \%$ & $62.3 \%$ & .035 & $59.9 \%$ & $57.3 \%$ & .572 \\
\hline Current smoker & $17.5 \%$ & $12.5 \%$ & .235 & $19.7 \%$ & $11.5 \%$ & .056 \\
\hline Atrial fibrillation & $4.3 \%$ & $5.0 \%$ & .781 & $6.4 \%$ & $4.5 \%$ & .469 \\
\hline Renal impairment & & & $<.001$ & & & .084 \\
\hline Creatinine clearance $>85 \mathrm{~mL} / \mathrm{min}$ & $27.5 \%$ & $15.8 \%$ & & $21.0 \%$ & $17.2 \%$ & \\
\hline Creatinine clearance $50-85 \mathrm{~mL} / \mathrm{min}$ & $50.7 \%$ & $47.1 \%$ & & $57.3 \%$ & $52.9 \%$ & \\
\hline Creatinine clearance $\leq 50 \mathrm{~mL} / \mathrm{min}$ & $18.9 \%$ & $31.0 \%$ & & $19.7 \%$ & $24.2 \%$ & \\
\hline On dialysis & $2.9 \%$ & $6.1 \%$ & & $1.9 \%$ & $5.7 \%$ & \\
\hline Extracardiac arteriopathy* & $21.8 \%$ & $31.0 \%$ & .010 & $21.0 \%$ & $25.5 \%$ & .338 \\
\hline Neurologic dysfunction* & $1.6 \%$ & $1.7 \%$ & .494 & $1.3 \%$ & $1.9 \%$ & .657 \\
\hline Previous cardiac surgery* & $1.7 \%$ & $1.4 \%$ & .082 & $4.5 \%$ & $0.6 \%$ & .069 \\
\hline Bronchodilators or steroids for lung disease* & $4.8 \%$ & $8.3 \%$ & .957 & $8.3 \%$ & $6.4 \%$ & .533 \\
\hline Critical preoperative state* & $4.5 \%$ & $3.6 \%$ & .548 & $4.5 \%$ & $1.9 \%$ & .178 \\
\hline Diabetes & & & .073 & & & .098 \\
\hline Only oral hypoglycemic agents & $25.6 \%$ & $15.8 \%$ & & $26.1 \%$ & $16.6 \%$ & \\
\hline On insulin & $25.3 \%$ & $33.8 \%$ & & $26.8 \%$ & $32.5 \%$ & \\
\hline NYHA class & & & .551 & & & .223 \\
\hline I & $34.8 \%$ & $32.4 \%$ & & $33.1 \%$ & $31.8 \%$ & \\
\hline II & $46.9 \%$ & $49.6 \%$ & & $52.2 \%$ & $45.9 \%$ & \\
\hline III & $17.6 \%$ & $17.2 \%$ & & $14.6 \%$ & $22.3 \%$ & \\
\hline IV & $0.7 \%$ & $0.8 \%$ & & $0.0 \%$ & $0.0 \%$ & \\
\hline CCS class 4 angina & $17.1 \%$ & $15.5 \%$ & .593 & $18.5 \%$ & $15.9 \%$ & .547 \\
\hline Left ventricular ejection fraction & & & .503 & & & .759 \\
\hline$>50 \%$ & $47.6 \%$ & $50.4 \%$ & & $46.5 \%$ & $48.4 \%$ & \\
\hline $31 \%-50 \%$ & $45.3 \%$ & $44.3 \%$ & & $45.9 \%$ & $45.9 \%$ & \\
\hline$\leq 30 \%$ & $7.1 \%$ & $5.3 \%$ & & $7.6 \%$ & $5.7 \%$ & \\
\hline Recent myocardial infarction within $90 \mathrm{~d}$ & $41.9 \%$ & $44.9 \%$ & .096 & $51.6 \%$ & $42.0 \%$ & .085 \\
\hline Systolic pulmonary artery pressure & & & .800 & & & .831 \\
\hline $31-55 \mathrm{~mm} \mathrm{Hg}$ & $15.2 \%$ & $13.0 \%$ & & $15.9 \%$ & $15.3 \%$ & \\
\hline$>55 \mathrm{~mm} \mathrm{Hg}$ & $1.0 \%$ & $1.7 \%$ & & $1.3 \%$ & $0.6 \%$ & \\
\hline Urgency* & & & .218 & & & .507 \\
\hline Elective & $64.0 \%$ & $50.4 \%$ & & $57.3 \%$ & $61.8 \%$ & \\
\hline Urgent & $32.5 \%$ & $45.2 \%$ & & $36.3 \%$ & $33.8 \%$ & \\
\hline Emergency operation & $3.5 \%$ & $4.4 \%$ & & $6.4 \%$ & $4.5 \%$ & \\
\hline Previous percutaneous coronary intervention & $17.8 \%$ & $29.4 \%$ & .000 & $23.6 \%$ & $24.2 \%$ & .884 \\
\hline Hemoglobin (g/dL) & $11.4 \pm 1.1$ & $11.3 \pm 1.2$ & .011 & $11.4 \pm 1.2$ & $11.3 \pm 1.2$ & 149 \\
\hline Moderate-to-severe anemia & $29.6 \%$ & $32.4 \%$ & .153 & $31.2 \%$ & $31.2 \%$ & - \\
\hline Diseased vessel & & & $<.001$ & & & .497 \\
\hline 1 & $1.4 \%$ & $14.4 \%$ & & $4.5 \%$ & $3.2 \%$ & \\
\hline 2 & $15.7 \%$ & $26.9 \%$ & & $28.7 \%$ & $24.8 \%$ & \\
\hline 3 & $82.9 \%$ & $58.7 \%$ & & $66.9 \%$ & $72.0 \%$ & \\
\hline Anastomoses/patient & $3.0 \pm 0.8$ & $2.3 \pm 1.2$ & & $2.8 \pm 1.2$ & $2.6 \pm 0.9$ & \\
\hline Anastomoses/patient & & & $<.001$ & & & .566 \\
\hline 1 & $1.4 \%$ & $28.8 \%$ & & $5.1 \%$ & $5.1 \%$ & \\
\hline 2 & $24.6 \%$ & $35.2 \%$ & & $48.4 \%$ & $49.7 \%$ & \\
\hline$\geq 3$ & $74.0 \%$ & $36.0 \%$ & & $46.5 \%$ & $45.2 \%$ & \\
\hline
\end{tabular}




\begin{tabular}{|c|c|c|c|c|c|c|}
\hline & \multicolumn{2}{|c|}{ Entire sample } & \multirow[b]{3}{*}{$P$ value } & \multicolumn{2}{|c|}{ Propensity matched } & \multirow[b]{3}{*}{$P$ valu } \\
\hline & On-pump & OPCAB & & On-pump & OPCAB & \\
\hline & $\mathbf{n}=\mathbf{5 7 8}$ & $\mathbf{n}=\mathbf{3 6 1}$ & & $\mathbf{n}=\mathbf{1 5 7}$ & $\mathbf{n}=\mathbf{1 5 7}$ & \\
\hline \multicolumn{7}{|c|}{ Preoperative medications within $7 \mathrm{~d}$} \\
\hline ACE inhibitor/Sartans & $63.5 \%$ & $72.3 \%$ & .266 & $66.2 \%$ & $74.5 \%$ & .077 \\
\hline Beta-blockers & $62.5 \%$ & $69.0 \%$ & .334 & $67.5 \%$ & $72.6 \%$ & .303 \\
\hline Calcium antagonists & $18.5 \%$ & $22.7 \%$ & .054 & $13.4 \%$ & $21.0 \%$ & .068 \\
\hline Statins & $68.9 \%$ & $75.9 \%$ & .776 & $74.5 \%$ & $72.6 \%$ & .686 \\
\hline Aspirin & $70.9 \%$ & $82.0 \%$ & .453 & $75.2 \%$ & $80.3 \%$ & .269 \\
\hline Ticlopidine or clopidogrel & $28.4 \%$ & $29.4 \%$ & .795 & $28.7 \%$ & $26.8 \%$ & .706 \\
\hline
\end{tabular}

Mean values \pm standard deviation or percentage of patients. $O P C A B$, Off-pump coronary artery bypass; NYHA, New York Heart Association; CCS, Canadian Cardiovascular Society; $A C E$, angiotensin-converting enzyme. *Variables definition according to euroSCORE II model. ${ }^{19}$ Creatinine clearance $(\mathrm{mL} / \mathrm{min})=[(140-$ age $) \times($ body weight $)] /$ $72 \times[$ serum creatinine $(\mathrm{mg} / \mathrm{dL})] \times 0.85$ (if female).

68 in the on-pump group and 58 in the OPCAB group. $\mathrm{Cu}-$ mulative mortality after the procedure by study groups in the whole population is shown in Figure 1, $A$, and in the propensity-matched group in Figure 1, $B$. After an initial lower risk, OPCAB surgery increased the cumulative mortality more than on-pump surgery (Figure 1). The Wilcoxon test for equality of overall survival (Figure 2, A and $B$ ) was not significant in both the entire population and the propensity-matched subgroup $(P=.432$ and $P=.491$, respectively). On Cox regression analysis including the type of surgery as the covariate, there was statistical evidence against the proportional hazards assumption $(P=.001)$. Figure 2 shows cumulative mortality, by type of surgery, separately for the intervals 0 to 30 days, 1 to 6 months, and more than 6 months from the procedure. During the first 30 days after the surgery (Figure 2, $A$ and $B$ ), there was a significantly greater mortality for on-pump surgery than OPCAB surgery. In the interval from 1 to 6 months (Figure 2, $C$ and $D$ ), there was a slightly, but not significant, lower incidence of events in the on-pump group than in the OPCAB group. Six months after surgery (Figure 2, $E$ and $F$ ), survivors who underwent on-pump surgery demonstrated a significantly better outcome than patients who underwent OPCAB. Table 3 shows the results of Cox regression analyses according to the 3 intervals adjusting for propensity score and anemia grade. The analysis corrected for anemia grade confirmed that, compared with the OPCAB group, the on-pump group had greater mortality within 30 days from the surgery with a lower incidence of fatal events

TABLE 2. Postoperative outcome according to coronary artery bypass grafting technique in the entire sample and the propensity-matched groups

\begin{tabular}{|c|c|c|c|c|c|c|c|}
\hline & \multicolumn{4}{|c|}{ Entire sample } & \multicolumn{3}{|c|}{ Propensity matched } \\
\hline & On-pump & ОРСАВ & & Adjusted & On-pump & OPCAB & \\
\hline & $\mathbf{n}=\mathbf{5 7 8}$ & $\mathrm{n}=361$ & $P$ value & $P$ value & $\mathbf{n}=\mathbf{1 5 7}$ & $\mathbf{n}=\mathbf{1 5 7}$ & $P$ value \\
\hline ICU duration of stay $>72 \mathrm{~h}$ & $22.1 \%$ & $18.0 \%$ & .051 & .003 & $28.0 \%$ & $17.8 \%$ & .026 \\
\hline Postoperative red blood cell & $64.2 \%$ & $58.4 \%$ & .001 & .007 & $68.2 \%$ & $55.4 \%$ & .020 \\
\hline Postoperative intra-aortic balloon pump & $1.6 \%$ & $0.8 \%$ & .287 & .080 & $1.9 \%$ & $0.0 \%$ & .250 \\
\hline Creatinine clearance reduction $>50 \%$ & $8.5 \%$ & $7.7 \%$ & .020 & .038 & $11.7 \%$ & $7.5 \%$ & .167 \\
\hline Need for hemodialysis & $5.2 \%$ & $4.7 \%$ & .915 & .889 & $4.5 \%$ & $5.4 \%$ & .782 \\
\hline Atrial fibrillation & $26.7 \%$ & $24.7 \%$ & .061 & .076 & $29.9 \%$ & $23.6 \%$ & .206 \\
\hline Reexploration due to bleeding & $3.0 \%$ & $3.0 \%$ & .706 & .766 & $3.8 \%$ & $2.5 \%$ & .530 \\
\hline Gastric complications & $1.0 \%$ & $1.9 \%$ & .242 & .427 & $1.3 \%$ & $2.5 \%$ & .341 \\
\hline Confusion/delirium & $2.3 \%$ & $2.2 \%$ & .119 & .095 & $3.2 \%$ & $1.9 \%$ & .484 \\
\hline Stroke or TIA & $0.9 \%$ & $0.3 \%$ & .139 & .355 & $2.5 \%$ & $0.6 \%$ & .215 \\
\hline Reintubation & $4.9 \%$ & $3.6 \%$ & .454 & .451 & $5.7 \%$ & $3.2 \%$ & .292 \\
\hline Sepsis & $1.4 \%$ & $1.1 \%$ & .404 & .787 & $1.9 \%$ & $1.3 \%$ & .657 \\
\hline Overall stay $>30 \mathrm{~d}$ & $4.0 \%$ & $2.5 \%$ & .723 & .668 & $1.3 \%$ & $0.6 \%$ & 1.000 \\
\hline Hospital mortality & $6.1 \%$ & $3.0 \%$ & .027 & .044 & $8.3 \%$ & $2.5 \%$ & .032 \\
\hline
\end{tabular}

Mean values \pm standard deviation or percentage of patients. Adjusted $P$ value at mixed logistic multivariate analysis correcting for propensity score. Creatinine clearance reduction calculated as the ratio between postoperative creatinine clearance at the creatinine peak and preoperative value. Sepsis was intended as evidence of infection and more than 1 of the following clinical findings (systemic inflammatory response syndrome criteria): body temperature $>38^{\circ} \mathrm{C}$ or $<36^{\circ} \mathrm{C}$, heart rate $>90$ beats/min, hyperventilation evidenced by respiratory rate $>20$ breaths/min, or partial pressure of arterial carbon dioxide $<32 \mathrm{~mm} \mathrm{Hg}$, white blood cell count $>12,000$ cells $/ \mu \mathrm{L}$ or $<4000 / \mu \mathrm{L}$. OPCAB, Off-pump coronary artery bypass; ICU, intensive care unit; TIA, transient ischemic attack. 

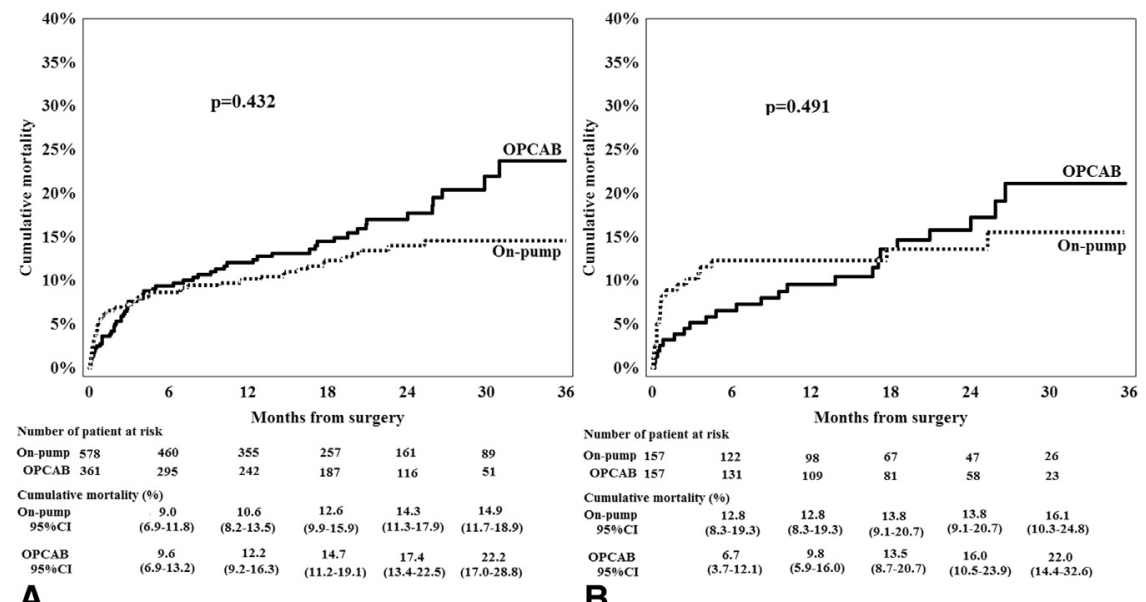

FIGURE 1. Overall cumulative mortality from cardiac surgery according to CABG technique in the entire sample (A) and the propensity-matched group (B). OPCAB, Off-pump coronary artery bypass; $C I$, confidence interval.
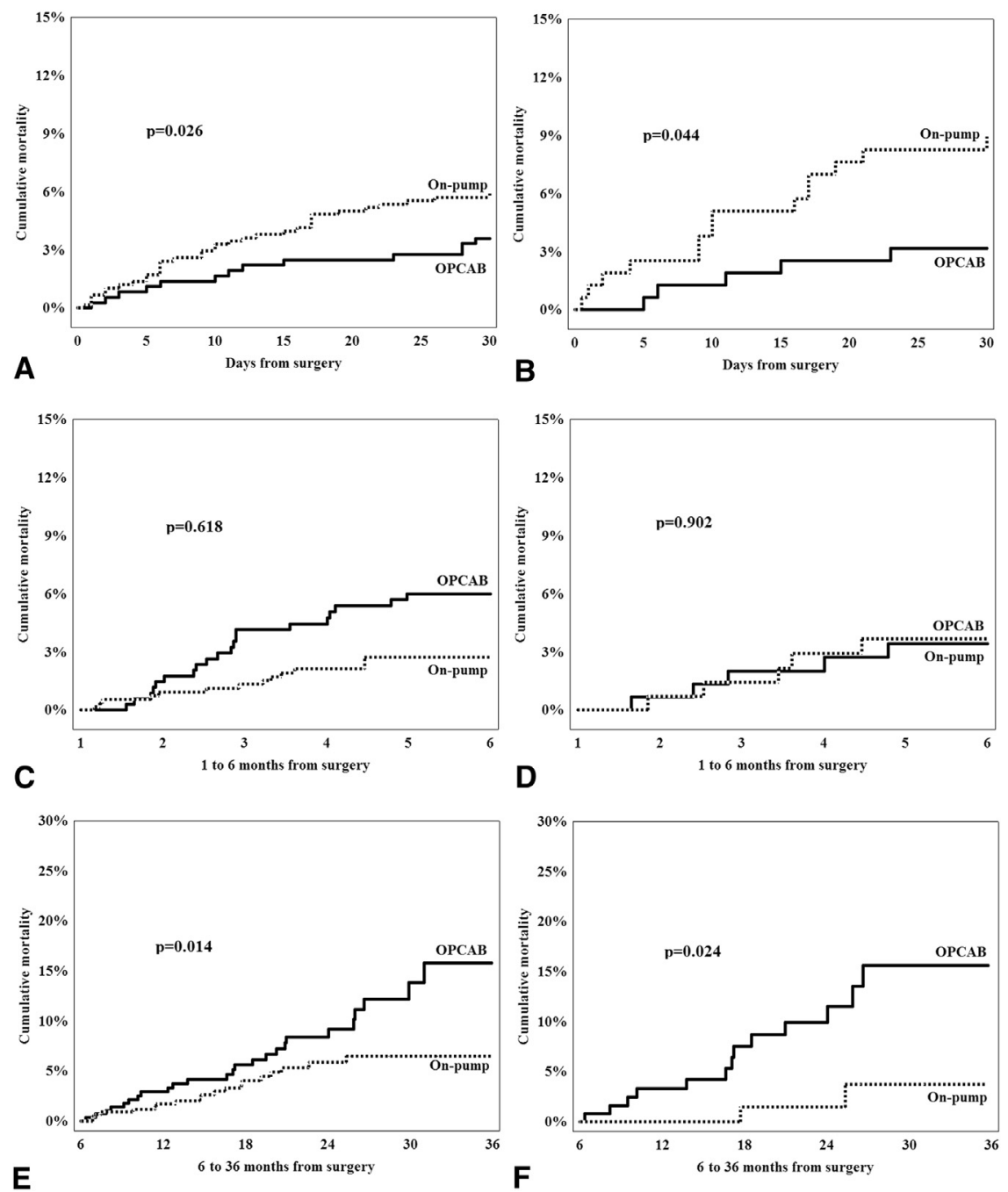

FIGURE 2. Cumulative mortality conditional on being alive at the beginning of each time interval according to CABG surgery in the entire sample (A, $\mathrm{C}$, and $\mathrm{E})$ and the propensity-matched group $(\mathrm{B}, \mathrm{D}$, and $\mathrm{F}) . O P C A B$, Off-pump coronary artery bypass. 
TABLE 3. Cox model hazard ratios

\begin{tabular}{|c|c|c|c|c|}
\hline & \multicolumn{2}{|c|}{ On-pump vs OPCAB } & \multirow{2}{*}{$\frac{P H \text { test }}{P \text { value }}$} & \multirow{2}{*}{$\frac{\text { LRT }}{P \text { value }}$} \\
\hline & HR & $P$ value & & \\
\hline \multicolumn{5}{|c|}{ Months after the surgery } \\
\hline Up to 1 & $2.67(1.13-6.32)$ & .026 & .702 & - \\
\hline $1-6$ & $0.79(0.32-1.96)$ & .618 & .964 & - \\
\hline$>6$ & $0.35(0.15-0.81)$ & .014 & .324 & - \\
\hline \multicolumn{5}{|c|}{ Adjusted for anemia grade } \\
\hline \multicolumn{5}{|c|}{ Months after the surgery } \\
\hline Up to 1 & $2.64(1.12-6.27)$ & .027 & .635 & .088 \\
\hline $1-6$ & $0.80(0.32-1.97)$ & .627 & .922 & .547 \\
\hline$>6$ & $0.34(0.15-0.79)$ & .013 & .249 & .879 \\
\hline
\end{tabular}

HR with $95 \% \mathrm{CI}$ adjusted for propensity score. LRT is for the interaction between anemia grade (moderate-to-severe vs mild) and surgical technique. OPCAB, Offpump coronary artery bypass; $P H$, proportional hazards (test of Cox model); $L R T$, likelihood ratio test; $H R$, hazard ratio. Bold indicates significant $P$ values.

after the first 6 months. No interaction was detected between the surgical technique and the anemia grade (likelihood-ratio test for the interaction was not significant in each analyzed interval) (Table 3). In the matched population, similar results were observed in the 3 intervals (Figure 2, $B, D$, and $F$ ) with HRs of 2.86 (1.03-7.93; $P=.044)$ during the first 30 days, 1.08 (0.31-3.74; $P=.902)$ from 1 to 6 months, and 0.18 (0.04-0.80; $P=.024) 6$ months after the surgery. Anemia grade was associated with overall mortality $(P=.022$ in the entire population and $P=.003$ ), with greater cumulative mortality in patients with moderate-to-severe anemia than in patients with mild anemia (24 months after the surgery, the estimated mortality was $19.3 \%$ vs $13.1 \%$ and $25.0 \%$ vs $10.3 \%$ in the matched group).

\section{DISCUSSION}

By using data on $\mathrm{CABG}$ procedures from a regional cardiac surgery registry, we found that the use of the OPCAB technique resulted in reduced rates of hospital mortality with a shorter ICU length of stay, lower red blood cell transfusion, and lower reduction in postoperative creatinine clearance compared with the on-pump technique. However, this initial benefit in mortality and morbidity was lost during follow-up with a greater number of deaths after hospital discharge in OPCAB cases.

The standard surgical approach for CABG includes the use of cardiac arrest coupled with CPB. The on-pump technique is associated with certain perioperative complications due to the use of $\mathrm{CPB}$ and manipulation of the ascending aorta: myocardial damage, cerebrovascular accidents, and potential neurocognitive, renal, and pulmonary dysfunction. ${ }^{1,2}$ To avoid these complications, the OPCAB technique was developed to perform surgery on the beating heart with the use of stabilizing devices. ${ }^{1,2}$ Currently, this technique is used in less than 1 in 5 patients who undergo surgical coronary revascularization according to data from the Society of Thoracic Surgeons Adult Cardiac Surgery Database regarding isolated primary CABG operations. ${ }^{23}$ However, the percentage of CABG operations performed off-pump has steadily declined over the last years: The use of off-pump procedures peaked in $2002(23 \%)$ and again in $2008(21 \%)$, followed by a progressive decline in off-pump frequency to $17 \%$ by $2012 .{ }^{23}$ In the Regional Cardiac Surgery Registry of Puglia, on approximately 4000 isolated CABG surgeries recorded from January 2011 to December 2013, approximately 1000 were OPCAB (27\%), with a trend for reduction (from $29 \%$ in 2011 to $25 \%$ in 2013). The proportion of patients who underwent OPCAB selected in our population was high $(37 \%)$ because of the high-risk profile of anemic patients for whom OPCAB was more frequently used than for nonanemic patients $(42 \%$ vs $34 \%$ ).

Several randomized controlled trials and registry data comparing on-pump and OPCAB have been published. . $-8,24-26^{2}$ Nevertheless, the 2 techniques generally have been considered similar for main short-term outcomes with large-scale prospective randomized studies that demonstrated the absence of superiority for mortality. ${ }^{7,8,27}$ OPCAB has been found to be associated with less bleeding, less renal dysfunction, a shorter length of hospital stay, and less neurocognitive dysfunction, with beneficial effects for patients at high risk for complications. $^{1,2,9,10}$ However, none of the previous prospective or retrospective studies have specifically addressed the outcome of anemic patients.

In our evaluation, the incidence of hospital mortality is high, particularly for on-pump cases. This is in line with other reports: Boening and colleagues ${ }^{28}$ reported $12.9 \%$ 30-day mortality in anemic patients undergoing on-pump CABG compared with $2.2 \%$ of nonanemic patients. ${ }^{28}$ Anemia is characterized by a significant increase of major morbidity and is considered a risk factor for operative mortality and complications in adult cardiac operations. ${ }^{13-17}$ Anemia can be considered a marker for severe underlying diseases and is often associated with other concomitant comorbidities. ${ }^{14}$ Moreover, preoperative anemia is one of the major determinants of low hematocrit values during CPB, and low hematocrit during $\mathrm{CPB}$ is an independent predictor of adverse outcome after CPB surgery. ${ }^{29}$ It is likely that anemic patients may experience (especially during $\mathrm{CPB}$ ) inadequate oxygen delivery during the operation, triggering a dysoxia-related multiorgan dysfunction. In our cohort, OPCAB was more frequently used in patients with preoperative anemia than in those with normal preoperative hemoglobin values, confirming that the OPCAB technique is usually preferred in highrisk patients. Our results suggest that patients undergoing $\mathrm{CABG}$ surgery with a low preoperative hemoglobin 
concentration have a lower hospital mortality rate if receiving the $\mathrm{OPCAB}$ technique, despite the fact that patients undergoing $\mathrm{OPCAB}$ had a greater risk profile than patients undergoing the on-pump procedure. However, to overcome the issue of different characteristics between groups, we performed a regression adjustment and propensity matching to compare groups of patients with the same preoperative and operative profile. The selection matching procedure, stratified by anemia grade and surgery center, performed well in balancing confounders between groups. Our results showed, irrespective of the adjustment method, a lower rate of hospital mortality (primary short-term end point) in the OPCAB group than in the on-pump group with reduced morbidity (secondary short-term end points). For anemic patients, we confirm data recently obtained from the Society of Thoracic Surgeons National Cardiac Database that compared OPCAB with on-pump CABG, and better early outcomes were observed for OPCAB correcting for preoperative risk (30 risk factors), center, and surgeon. ${ }^{30}$ Moreover, procedures with a higher predicted risk of operative mortality had the largest apparent benefit, similar to our results in anemic patients. ${ }^{30}$

Anemia could be corrected during and after the operation. Patients undergoing CPB more frequently received red blood cell transfusion than patients undergoing OPCAB. Unfortunately, our database does not allow specifying when transfusions occurred, but it is likely that a certain amount of transfusions were prescribed perioperatively to correct hemodilution caused by CPB. Transfusion of blood products is another recognized risk factor for adverse events after cardiac surgery. ${ }^{31}$ The pathophysiologic mechanism by which transfusions might harm has not been fully elucidated, but it is known that erythrocytes undergo irreversible morphologic and biochemical changes during storage. As a result, after transfusion, they can promote a proinflammatory state, impair tissue oxygen delivery, and exacerbate tissue oxidative stress. This in turn can contribute to organ dysfunction and explain, at least in part, the increased hospital mortality in on-pump cases.

Conversely, the initial advantage in mortality and morbidity observed in the short-term was lost during follow-up. Mortality after hospital discharge, particularly the first 6 months after the surgery, was significantly worse in the OPCAB group. We are unaware of the cause of death, but several previous reports have indicated decreased graft patency, ${ }^{11}$ fewer grafts, and incomplete revascularization as a possible consequence of the OPCAB operation. ${ }^{12}$ In a large registry, Hannan and colleagues ${ }^{25}$ showed that the initial OPCAB benefit in mortality was lost during the 3-year follow-up, with a significantly greater need for repeated revascularization in these patients. ${ }^{25}$

\section{Study Limitations}

The present multicenter study is subject to all the limitations of observational studies, although the statistical analyses aimed to control for confounding factors and to compare groups of patients with the same preoperative and operative profile. The association between surgical technique and postoperative outcome was confirmed in the matched subgroups, and differences in mortality between on-pump and OPCAB cases were also evaluated correcting for patients' anemia grade. No interaction was detected between surgical technique and anemia grade, but a greater sample size is required to better explore this relationship. Our study population included consecutive patients who underwent isolated CABG surgery in 5 of 7 centers of Puglia over 36 months with midterm mortality automatically available for residents in the region. The 74 excluded patients (postdischarge vital status unavailable for nonresident in Puglia region) confirmed general short-term results: no deaths in the 21 patients undergoing OPCAB and 3 deaths in the 53 patients undergoing on-pump surgery $(0 \%$ and $6 \%$, respectively).

\section{CONCLUSIONS}

In patients with preoperative anemia, OPCAB leads to better short-term results and on-pump CABG performs better in the midterm with fewer fatal events during follow-up.

\section{Conflict of Interest Statement}

Authors have nothing to disclose with regard to commercial support.

\section{References}

1. Hillis LD, Smith PK, Anderson JL, Bittl JA, Bridges CR, Byrne JG, et al. 2011 ACCF/AHA guideline for coronary artery bypass graft surgery: executive summary: a report of the American College of Cardiology Foundation/American Heart Association Task Force on Practice Guidelines. J Thorac Cardiovasc Surg. 2012;143:4-34.

2. Authors/Task Force members, Windecker S, Kolh P, Alfonso F, Collet JP, Cremer J, Falk V, et al. 2014 ESC/EACTS Guidelines on myocardial revascularization: The Task Force on Myocardial Revascularization of the European Society of Cardiology (ESC) and the European Association for Cardio-Thoracic Surgery (EACTS) developed with the special contribution of the European Association of Percutaneous Cardiovascular Interventions (EAPCI). Eur Heart J. 2014;35:2541-619.

3. Nathoe HM, van Dijk D, Jansen EW, Suyker WJ, Diephuis JC, van Boven WJ, et al. A comparison of on-pump and off-pump coronary bypass surgery in lowrisk patients. N Engl J Med. 2003;348:394-402.

4. Légaré JF, Buth KJ, King S, Wood J, Sullivan JA, Hancock Friesen C, et al. Coronary bypass surgery performed off pump does not result in lower in-hospita morbidity than coronary artery bypass grafting performed on pump. Circulation. 2004; 109:887-92.

5. Straka Z, Widimsky P, Jirasek K, Stros P, Votava J, Vanek T, et al. Off-pump versus on-pump coronary surgery: final results from a prospective randomized study PRAGUE-4. Ann Thorac Surg. 2004;77:789-93.

6. Puskas JD, Williams WH, Mahoney EM, Huber PR, Block PC, Duke PG, et al Off-pump vs conventional coronary artery bypass grafting: early and 1-year graf patency, cost, and quality-of-life outcomes: a randomized trial. JAMA. 2004;291 1841-9. 
7. Shroyer AL, Grover FL, Hattler B, Collins JF, McDonald GO, Kozora E, et al. On-pump versus off-pump coronary-artery bypass surgery. $N$ Engl J Med. 2009;361:1827-37.

8. Lamy A, Devereaux PJ, Prabhakaran D, Taggart DP, Hu S, Paolasso E, et al. Off pump or on-pump coronary-artery bypass grafting at 30 days. $N$ Engl J Med 2012:366:1489-97.

9. Puskas JD, Thourani VH, Kilgo P, Cooper W, Vassiliades T, Vega JD, et al. Offpump coronary artery bypass disproportionately benefits high-risk patients. Ann Thorac Surg. 2009;88:1142-7.

10. Lemma MG, Coscioni E, Tritto FP, Centofanti P, Fondacone C, Salica A, et al On-pump versus off-pump coronary artery bypass surgery in high-risk patients: operative results of a prospective randomized trial (on-off study). J Thorac Cardiovasc Surg. 2012;143:625-31.

11. Houlind K, Fenger-Grøn M, Holme SJ, Kjeldsen BJ, Madsen SN, Rasmussen BS, et al. Graft patency after off-pump coronary artery bypass surgery is inferior even with identical heparinization protocols: results from the Danish On-pump Versus Off-pump Randomization Study (DOORS). J Thorac Cardiovasc Surg. 2014; 148:1812-9.e2

12. Takagi $\mathrm{H}$, Umemoto $\mathrm{T}$, All-Literature Investigation of Cardiovascular Evidence (ALICE) Group. Worse long-term survival after off-pump than onpump coronary artery bypass grafting. J Thorac Cardiovasc Surg. 2014;148: 1820-9.e1

13. Zindrou D, Taylor KM, Bagger JP. Preoperative haemoglobin concentration and mortality rate after coronary artery bypass surgery. Lancet. 2002;359: 1747-8.

14. Kulier A, Levin J, Moser R, Rumpold-Seitlinger G, Tudor IC, Snyder-Ramos SA, et al. Impact of preoperative anemia on outcome in patients undergoing coronary artery bypass graft surgery. Circulation. 2007;116:471-9.

15. Williams ML, He X, Rankin JS, Slaughter MS, Gammie JS. Preoperative hematocrit is a powerful predictor of adverse outcomes in coronary artery bypass graft surgery: a report from the Society of Thoracic Surgeons Adult Cardiac Surgery Database. Ann Thorac Surg. 2013;96:1628-34.

16. Ranucci M, Di Dedda U, Castelvecchio S, Menicanti L, Frigiola A, Pelissero G, et al. Impact of preoperative anemia on outcome in adult cardiac surgery: a propensity-matched analysis. Ann Thorac Surg. 2012;94:1134-41.

17. Scrascia G, Guida P, Caparrotti SM, Capone G, Contini M, Cassese M, et al. Incremental value of anemia in cardiac surgical risk prediction with the European System for Cardiac Operative Risk Evaluation (EuroSCORE) II Model. Ann Thorac Surg. 2014;98:869-75.

18. Paparella D, Guida P, Bisceglia L, Caparrotti S, Carbone C, Cassese M, et al Development and results of Puglia adult cardiac surgery registry. J Cardiovasc Med (Hagerstown). 2014;15:810-6.

19. Nashef SA, Roques F, Sharples LD, Nilsson J, Smith C, Goldstone AR, et al. EuroSCORE II. Eur J Cardiothorac Surg. 2012;41:734-44.

20. World Health Organization. Haemoglobin concentrations for the diagnosis of anaemia and assessment of severity. Vitamin and Mineral Nutrition Information
System. Geneva: World Health Organization; 2011 (WHO/NMH/NHD/MNM/ 11.1). Available at: http://www.who.int/vmnis/indicators/haemoglobin.pdf. Accessed October 3, 2014

21. D'Agostino RB Jr. Propensity scores in cardiovascular research. Circulation. 2007; 115:2340-3.

22. Shahian DM, O'Brien SM, Sheng S, Grover FL, Mayer JE, Jacobs JP, et al. Predictors of long-term survival after coronary artery bypass grafting surgery: results from the Society of Thoracic Surgeons Adult Cardiac Surgery Database (the ASCERT study). Circulation. 2012;125: 1491-500.

23. Bakaeen FG, Shroyer AL, Gammie JS, Sabik JF, Cornwell LD, Coselli JS, et al. Trends in use of off-pump coronary artery bypass grafting: results from the Society of Thoracic Surgeons Adult Cardiac Surgery Database. J Thorac Cardiovasc Surg. 2014;148:856-64.

24. Khan NE, De Souza A, Mister R, Flather M, Clague J, Davies S, et al. A randomized comparison of off-pump and on-pump multivessel coronary-artery bypass surgery. N Engl J Med. 2004;350:21-8.

25. Hannan EL, Wu C, Smith CR, Higgins RS, Carlson RE, Culliford AT, et al. Offpump versus on-pump coronary artery bypass graft surgery: differences in short-term outcomes and in long-term mortality and need for subsequent revascularization. Circulation. 2007;116:1145-52.

26. Kuss O, von Salviati B, Börgermann J. Off-pump versus on-pump coronary artery bypass grafting: a systematic review and meta-analysis of propensity score analyses. J Thorac Cardiovasc Surg. 2010;140:829-35.

27. Sellke FW, DiMaio JM, Caplan LR, Ferguson TB, Gardner TJ, Hiratzka LF, et al. Comparing on-pump and off-pump coronary artery bypass grafting: numerous studies but few conclusions: a scientific statement from the American Heart Association council on cardiovascular surgery and anesthesia in collaboration with the interdisciplinary working group on quality of care and outcomes research. Circulation. 2005;111: 2858-64.

28. Boening A, Boedeker RH, Scheibelhut C, Rietzschel J, Roth P, Schönburg M. Anemia before coronary artery bypass surgery as additional risk factor increases the perioperative risk. Ann Thorac Surg. 2011;92: 805-10.

29. Karkouti K, Beattie WS, Wijeysundera DN, Rao V, Chan C, Dattilo KM, et al. Hemodilution during cardiopulmonary bypass is an independent risk factor for acute renal failure in adult cardiac surgery. J Thorac Cardiovasc Surg. 2005; 129:391-400.

30. Polomsky M, He X, O'Brien SM, Puskas JD. Outcomes of off-pump versus on-pump coronary artery bypass grafting: impact of preoperative risk. $J$ Thorac Cardiovasc Surg. 2013;145:1193-8.

31. Koch CG, Li L, Duncan AI, Mihaljevic T, Cosgrove DM, Loop FD, et al. Morbidity and mortality risk associated with red blood cell and bloodcomponent transfusion in isolated coronary artery bypass grafting. Crit Care Med. 2006;34:1608-16.

Readers who found these articles interesting may also like to read the following papers found in recent and future issues of our sister publications, Seminars in Thoracic and Cardiovascular Surgery and Operative Techniques in Thoracic and Cardiovascular Surgery!

News and Views: Stephen Fremes. Outcomes of Arterial Revascularization. Semin Thorac Cardiovasc Surg. Autumn 2014;26(3): 174-175.

News and Views: Brian Buxton. Editorial on Multiple Arterial Grafting. Semin Thorac Cardiovasc Surg. Autumn 2014;26(3): 176-178.

News and Views: A. P. Kappetein. Role of PCI in the Treatment of Left Main Coronary Disease. Semin Thorac Cardiovasc Surg. Autumn 2014;26(3):187-191.

State of the Art: Victor Ferraris. Use of Anti-platelet Drugs after Cardiac Operations. Semin Thorac Cardiovasc Surg. Autumn 2014;26(3):223-230.

John Conte. Repair of Postinfarct Ventricular Septal Defect: Anterior Apical Ventricular Septal Defect. Oper Tech Thorac Cardiovasc Surg. Spring 2014;19(1):96-114.

Thomas Gleason. Repair of Postinfarction Ventricular Septal Defect: Posterior Inferior Ventricular Septal Defect. Oper Tech Thorac Cardiovasc Surg. Spring 2014;19(1):115-126. 
TABLE E1. Mixed logistic regression model: Predictors of on-pump surgery

\begin{tabular}{lcc}
\hline & Coefficient \pm SE & $P$ value \\
\hline Age (y) & $-0.006 \pm 0.012$ & .613 \\
Hyperlipidemia & $0.371 \pm 0.214$ & .083 \\
Renal impairment & & \\
$\quad$ Creatinine clearance $>85 \mathrm{~mL} / \mathrm{min}$ & Reference & \\
Creatinine clearance $50-85 \mathrm{~mL} / \mathrm{min}$ & $-0.396 \pm 0.268$ & .141 \\
Creatinine clearance $\leq 50 \mathrm{~mL} / \mathrm{min}$ & $-0.861 \pm 0.323$ & .008 \\
On dialysis & $-0.774 \pm 0.512$ & .130 \\
Extracardiac arteriopathy & $-0.358 \pm 0.215$ & .096 \\
Previous percutaneous coronary intervention & $-0.414 \pm 0.221$ & .061 \\
Hemoglobin (g/dL) & $0.047 \pm 0.083$ & .569 \\
Diseased vessel & & \\
1 & Reference & \\
2 & $-0.425 \pm 0.671$ & .527 \\
3 & $-0.367 \pm 0.671$ & .584 \\
Anastomoses/patient & & \\
1 & Reference & \\
2 & $3.508 \pm 0.578$ & $<.001$ \\
$\geq 3$ & $5.391 \pm 0.604$ & $<.001$ \\
\hline
\end{tabular}

$S E$, Standard error. 